Indian J Anim Health (2021), 60(2): 298-299

DOI: https://doi.org/10.36062/ijah.2021.03821

\title{
Successful therapeutic management of NSAID induced type III abomasal ulcer in a Jersey crossbred bull
}

\author{
K. Sasikala ${ }^{1 *}$, S. Sivaraman ${ }^{2}$, E.Venkatesakumar $^{1}$, K. Mohanambal ${ }^{1}$, R. Ravi ${ }^{1}$ \\ and P. K. Ramkumar ${ }^{1}$
}

${ }^{1}$ Department of Veterinary Clinical Medicine, Veterinary College and Research Institute, Namakkal - 637 002, Tamil Nadu, India; ${ }^{2}$ Veterinary Clinical Complex, Veterinary College and Research Institute, Namakkal - 637 002, Tamil Nadu, India

\begin{abstract}
An eleven years old Jersey crossbred bull was presented with a history of inappetance, melena, bruxism and mild tympany for three days. The animal was reported to be treated with flunixin meglumine and phenylbutazone for pyrexia. Clinical examination revealed pale pink mucous membranes, mild tympany and dark tarry coloured dung in rectal examination. Hematology revealed anaemia, neutrophilia with leukocytosis. Peripheral blood smear and fine-needle aspiration biopsy were negative for blood protozoan diseases. The dung sample was positive for occult blood. Copious free flow of peritoneal fluid was seen on abdominocentesis near the abomasal area and anechoic fluid was noticed on ultrasonographic examination. The case was diagnosed as NSAID induced type III abomasal ulcer. The animal was treated with streptopenicillin, pantoprazole, ferritas and oral antacids for five days. The animal recovered uneventfully following treatment.
\end{abstract}

Key words: Cattle, Melena, NSAID, Peritonitis, Type III abomasal ulcer

Non-steroidal anti-inflammatory drugs are effective therapeutic agents with analgesic, antiinflammatory, and antipyretic properties. Side effects of the NSAIDs are more often reported in small animals, horses, humans and rats. Abomasal ulceration is common in cattle; however, it is rarely associated with the use of NSAID (Gomes et al., 2008). Calves and adult cows treated with NSAIDs developed abomasal ulcers. It was seen in calves receiving flunixin and in bulls treated with NSAIDs for a prolonged period for musculoskeletal disorders (Divers and Peek, 2008). Abomasal ulceration occurred in mature cattle and calves and might cause acute abomasal hemorrhage with indigestion, melena and sometimes perforation, resulted in painful acute local peritonitis or acute diffuse peritonitis (Constable et al., 2017).

An eleven years old Jersey crossbred bull was presented with a history of inappetance, melena and mild tympany for three days. The animal was reported to be treated for pyrexia with flunixin meglumine (@2 mg/kg) and phenylbutazone (@20 mg/kg) for a week. On clinical examination, the animal was dull and depressed with pale pink mucous membranes. Respiratory rate was 48 breaths/min and the pulse rate was 95 beats $/ \mathrm{min}$. The animal exhibited bruxism, mild abdominal pain and absence of ruminal motility with mild tympany. Foul-smelling dark tarry coloured watery diarrhoea was noticed in rectal examination (Fig.1). Hematology revealed anaemia, [hemoglobin $(5.4 \mathrm{~g} / \mathrm{dL})$, packed cell volume $(16.21 \%)$ and red blood cells $\left(2.98 \times 10^{6} /\right.$ cumm $\left.)\right]$ neutrophilia $(85 \%)$ with leucocytosis $\left(20.05 \times 10^{3} /\right.$ cumm $)$. Serum biochemical values were within the normal range. Peripheral blood smear and fine-needle aspiration biopsy samples were negative for blood protozoan diseases. The faecal sample was positive $(+++)$ for occult blood. Copious free flow of clear peritoneal fluid was noticed on abdominocentesis. Ultrasonogram obtained from the ventral abdominal wall showed anechoic fluid indicative of mild peritonitis near the reticular area (Fig. 2). Based on the history, clinical, laboratory and ultrasonographic

\footnotetext{
*Corresponding Author, E mail: sasikalakaliapan@gmail.com
} 
Indian Journal of Animal Health, December, 2021

Management of NSAID induced type III abomasal ulcer in a bull

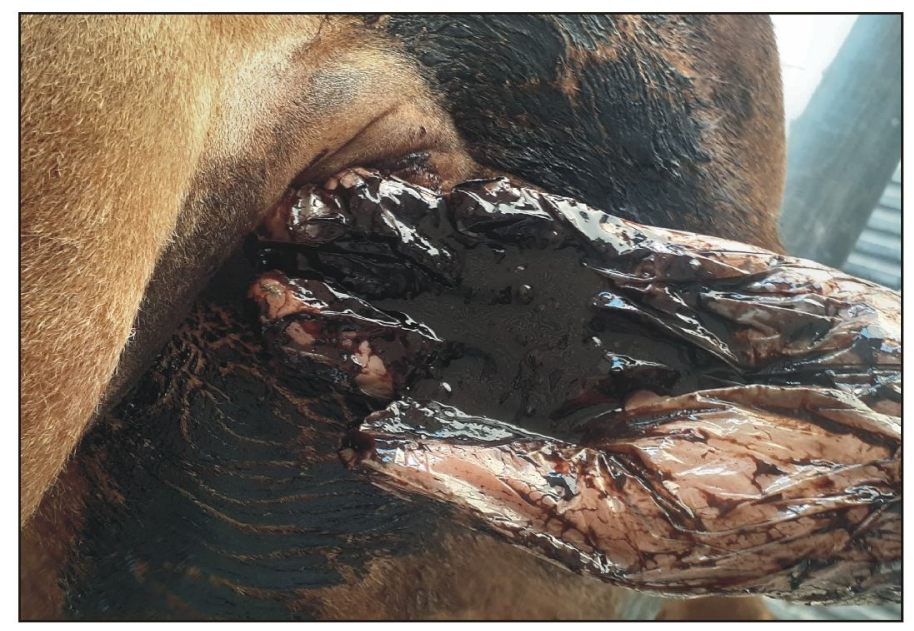

Fig. 1. Dark tarry coloured dung (Melena) - Before treatment

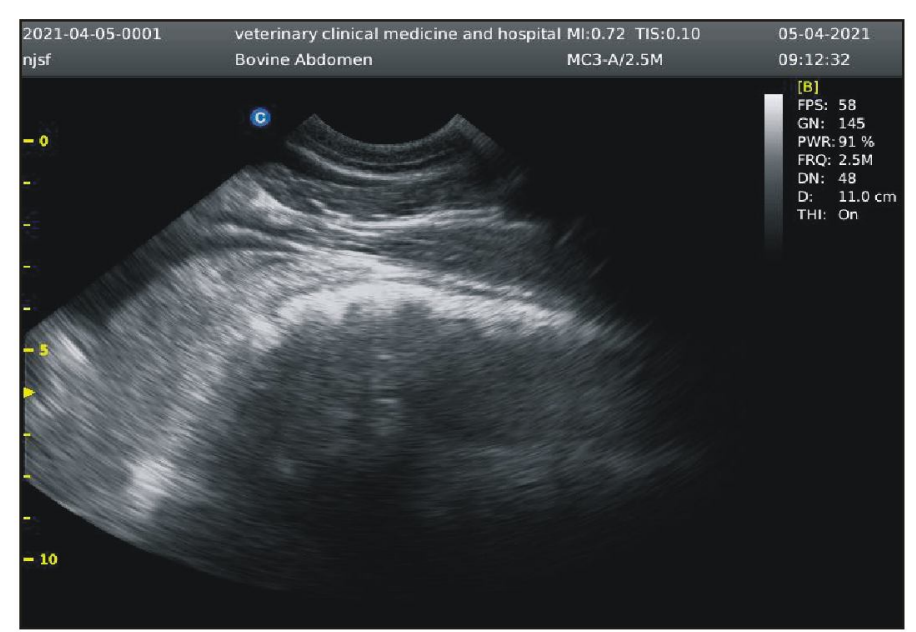

Fig. 2. Ultrasonogram of the reticular area showing anechoic peritoneal fluid (F) - Peritonitis

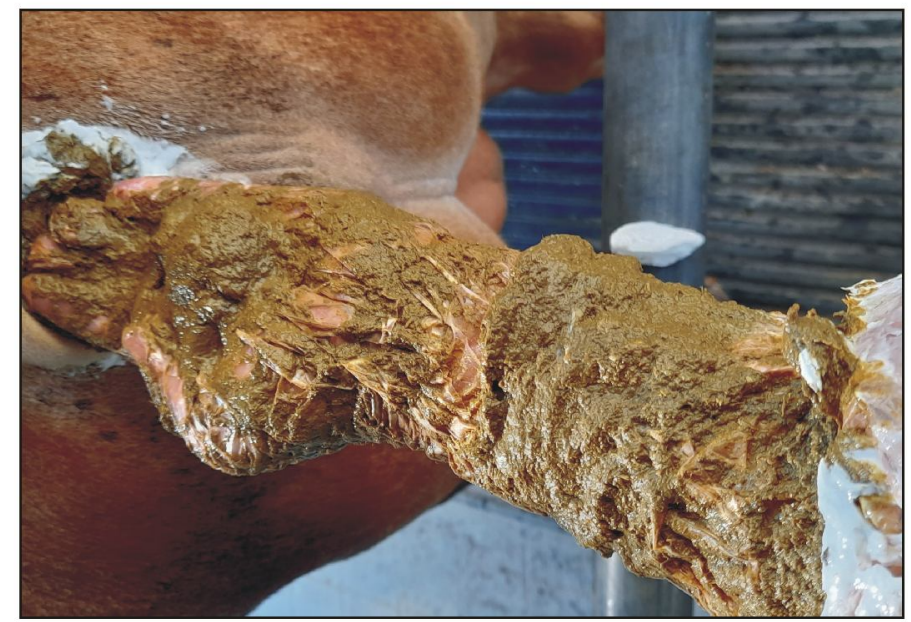

Fig. 3. Normal dung - After treatment 
findings the case was diagnosed as NSAID induced type III abomasal ulcer and therapeutic measures were undertaken immediately.

The animal was administered with streptopenicillin (7.5 g IM), pantoprazole (@ 1 $\mathrm{mg} / \mathrm{kg} \mathrm{IV}$ ), ferritas (5 mL IM on alternate days), tribivet $(20 \mathrm{~mL} \mathrm{IV})$, oral antacids (magnesium carbonate@500 g orally). The treatment was continued for five days. There was an improvement in the colour of the dung and feeding habit on the next day of treatment. Bull voided normal dung on the $4^{\text {th }}$ day of treatment (Fig. 3).

NSAIDs are commonly used in veterinary medicine for their antipyrogenic property and pain management. It causes mucosal irritation, decreases prostaglandin production and gastric blood flow which make the stomach more prone to ulceration (Enberg et al., 2006). Penetration of full thickness of the abomasal wall resulted in leakage of abomasal contents with subsequent acute local peritonitis in type III abomasal ulcer. Melena was the pathognomonic sign of an acute bleeding ulcer of the abomasum (Constable et al., 2017). Bruxism, mild abdominal pain, partial anorexia, decreased ruminal motility and

\section{REFERENCES}

Legendre L, 2005. Maxillofacial fracture repairs. Vet Clin North Am Small Anim Pract, 35(4): 985-1008, doi: 10.1016/j.cvsm.2005.03.003

Braun U, Reif C, Nuss K, Hilbe M and Gerspach C, 2019. Clinical, laboratory and ultrasonographic findings in 87 cows with type-4 abomasal ulcer. BMC Vet Res, 15: 100, doi: 10.1186/s12917-0191844-6

Constable PD, Hinchcliff KW, Done SH and Grunberg W, 2017. Veterinary Medicine. A textbook of the diseases of cattle, horses, sheep, pigs and goats. $11^{\text {th }}$ edn., W. B. Saunders Elsevier, Philadelphia, pp 518-522

Divers TJ and Peek SF, 2008. Rebhun's Diseases of Dairy Cattle. $2^{\text {nd }}$ edn., W. B. Saunders Elsevier, Philadelphia, pp 167-174

Enberg TB, Braun LD and Kuzma AB, 2006. Gastrointestinal perforation in five dogs associated with the administration of meloxicam. mild ruminal tympany in the present case were in concurrence with Braun et al. (2019). Therapy followed in the present case was in concurrence with Constable et al. (2017). Medical therapy for abomasal ulcer with localized peritonitis included stall rest and broad-spectrum antibiotics (Divers and Peek, 2008) and the use of streptopenicillin was found effective in cattle with traumatic reticuloperitonitis (Sasikala et al., 2016). Pantoprazole (@ 1 mg/kg) was a safe adjunctive gastroprotectant therapy in hospitalized ruminants (Smith et al., 2020). Simultaneous use of two NSAIDs for long period, old age of the bull, and concentrate feeding made the bull vulnerable to type III abomasal ulcer in the present case. NSAIDs should be used judicially in buiatric practice.

Conflict of interest: Authors have no conflict of interest in this study.

\section{ACKNOWLEDGMENTS}

The authors are very thankful to the Dean, Veterinary College and Research Institute, Namakkal for the facilities provided during the study.

J Vet Emerg Critic Care, 16(1): 34-43, doi: 10.1111/j.1476-4431.2005.00157.x

Gomes DC, Murakawa DM, Varaschin MS, Wouters F, Mesquita LP et al., 2008. Perforated duodenal ulcer associated with nonsteroidal anti-inflammatory drug administration in a dairy cow. Braz $\mathrm{J}$ Vet Pathol, 1(2): 56-58

Sasikala K, Vijayakumar G, Sivaraman S and Balasubramaniam GA, 2016. Endoscopic evaluation and therapeutic management of diseases of reticulum in cattle. M.V.Sc., Dissertation, Tamil Nadu Veterinary and Animal Sciences University, Chennai-600051, Tamil Nadu, India

Smith JS, Kosusnik AR and Mochel JP, 2020. A retrospective clinical investigation of the safety and adverse effects of pantoprazole in hospitalized ruminants. Front Vet Sci, 7: 97, doi: 10.3389/ fvets. 2020.00097

Received - 06.05.2021, Accepted - 25.06.2021, Published - 30.08.2021 (Online), 01.12.2021 (Print)

Section Editor: Prof. S. K. Nandi, Associate Editor 